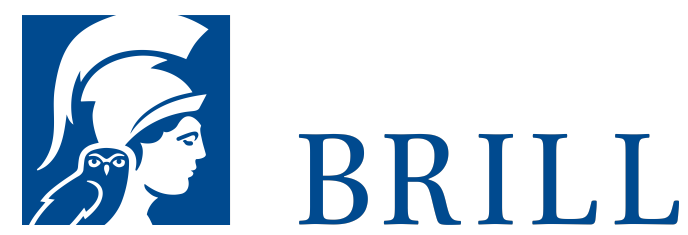

\title{
Kölner Papyri (P. Köln) Band 16
}

Author: Thomas Backhuys

Die Nordrhein-Westfälische Akademie der Wissenschaften und der Künste ist eine Vereinigung der führenden Forscherinnen und Forscher des Landes. Sie wurde 1970 als Nachfolgeeinrichtung der Arbeitsgemeinschaft für Forschung des Landes Nordrhein-Westfalen gegründet. Die Akademie ist in drei wissenschaftliche Klassen für Geisteswissenschaften, für Naturwissenschaften und Medizin sowie für Ingenieur- und Wirtschaftswissenschaften und in eine Klasse der Künste gegliedert.

Mit Publikationen zu den wissenschaftlichen Vorträgen in den Klassensitzungen, zu öffentlichen Veranstaltungen und Symposien will die Akademie die Fach- und allgemeine Öffentlichkeit über die Arbeiten der Akademie und ihrer Forschungsstellen informieren.

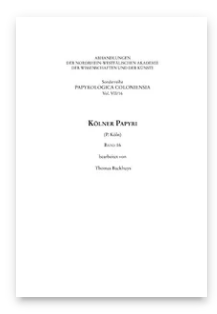

Published: 22 Jun 2020

Pages: $\mathrm{X}+334$ Seiten, $18 \mathrm{~s} / \mathrm{w}$ Abb., 4 s/w Tab.

Subjects:

Ancient History, Classical Studies

Publisher: Brill | Schöningh

Series:

Sonderreihe der Abhandlungen

Papyrologica Coloniensia,

Volume: 7/16

E-Book (PDF)

ISBN: 978-3-

657-71538-1

Price:

Paperback ISBN: 978-3506-71538-8

Price: 
Please send your order to: Brockhaus/Commission Tel: +49(o)71 541327 9216 | E-Mail: brill@ $\underline{\text { brocom.de }}$

For questions please contact: Brill Deutschland GmbH

Wollmarktstraße 115 | 33098 Paderborn | Germany

Tel: +49 (o)5251 69975 o | E-Mail: sales@brill.com. 